\title{
Give Until It Hurts
}

\author{
Allahbadia Gautam
}

Published online: 12 March 2014

(C) Federation of Obstetric \& Gynecological Societies of India 2014

The Journal of Obstetrics \& Gynecology of India needs the services of its readers who are experienced with publishing. One big rate-limiting step of our publication releasing its bi-monthly issues on time is the process of peer review. In the last 20 years that I have worked my way up the ladder, the darkest secret of delayed volumes has been the indifference of the peer reviewers and inordinately delayed submissions. If we need to compete with the best in global academia, then we will need to have selfless, hard-working, and sincere volunteers for the Journal's peer review process who can write to me directly with their field of expertise. Peer review is the evaluation of work by one or more people of similar competence to the producers of the work (peers). It constitutes a form of self-regulation by qualified members of a profession within the relevant field. Peer review methods are employed to maintain standards of quality, improve performance, and provide credibility. In academia, peer review is often used to determine an academic paper's suitability for publication. Pragmatically, peer review refers to the work done during the screening of submitted manuscripts. This process encourages authors to meet the accepted standards of their discipline and reduces the dissemination of irrelevant findings, unwarranted claims, unacceptable interpretations, and personal views.

Allahbadia G. ( $\square)$

Rotunda-The Center for Human Reproduction, 36 Turner Road, \#101, 1st Floor B Wing, Bandra (W), Mumbai 400 050, India

e-mail: ivfwaladoc@gmail.com
Publications that have not undergone peer review are likely to be regarded with suspicion by academic scholars and professionals. At a journal, the task of picking reviewers typically falls to an editor. Recruiting referees is a political art, because referees, and often editors, are usually not paid, and reviewing takes time away from the referee's main activities, such as his or her own research. I want to turn this process of selection into one of experts giving their time to bring better research to our medical fraternity and to the country.

In earlier periods, editors of journals often made publication decisions without seeking outside input. For example, Albert Einstein's revolutionary "Annus Mirabilis" papers in the 1905 issue of Annalen der Physik were peerreviewed by the journal's editor-in-chief, Max Planck, and its co-editor, Wilhelm Wien, both future Nobel prize winners and together experts on the topics of these papers. The first recorded editorial pre-publication peer-review process was at The Royal Society in 1665 by the founding editor of Philosophical Transactions of the Royal Society, Henry Oldenburg [1-3]. The first peer-reviewed publication might have been the Medical Essays and Observations published by the Royal Society of Edinburgh in 1731. The present-day peer-review system evolved from this eighteenth-century process [4]. Philosophical Transactions from its outset did not publish all the material it received; the Council of the Society reviewed the contributions Oldenburg received before approving a selection of them for publication. Albeit primitive, this is the first recorded instance of "peer review". 
The four principles of Oldenburg's journal: registration, dissemination, peer review, and archival record are so fundamental to the way scientists behave and how science is carried out that all subsequent journals, even those published electronically in the 21 st century, have conformed to Oldenburg's model.

Peer review in its current form is relatively recent; the journal Nature instituted formal peer review only in 1967 [5]. The work may be accepted, considered acceptable with revisions, or rejected. Peer review requires a community of experts in a given (and often narrowly defined) field, who are qualified and able to perform reasonably impartial review.

Although generally considered essential to academic quality, and used in most important scientific publications, peer review has been criticized as ineffective, slow, and is often misunderstood. Other critiques of the current peer review process from concerned scholars has stemmed from recent controversial studies published by two researchers from the Harvard-Smithsonian Center for Astrophysics and NASA [6]. These two published articles are now case studies of peer review failure. There have also recently been experiments with wiki-style, signed, peer reviews, for example, in an issue of the Shakespeare Quarterly [7].

At the end of the day, the decision whether or not to publish a scholarly article, or what should be modified before publication, lies with the editor of the journal to which the manuscript has been submitted. These individuals usually refer to the opinion of one or more reviewers or referees in making their decision. Thus it is normal for manuscripts to be sent to one or more external reviewers. During this process, the role of the referees is advisory. The editor is typically under no obligation to accept the opinions of the referees, though he will most often do.

Some medical journals, usually following the open access model, have begun posting on the Internet the prepublication history of each individual article, from the original submission to reviewers' reports, authors' comments, and revised manuscripts [8].

Peer review failures occur when a peer-reviewed article contains fundamental errors that undermine at least one of its main conclusions. Many journals have no procedure to deal with peer review failures beyond publishing letters to the editor [9, 10]. Peer review in scientific journals assumes that the article reviewed has been honestly prepared, and the process is not designed to detect fraud [11]. An experiment on peer review with a fictitious manuscript found that peer reviewers fail to detect some manuscript errors, and the majority of reviewers may not notice that the conclusions of the paper are unsupported by its results [12]. When peer review fails and a paper is published with fraudulent or otherwise irreproducible data, the paper may be retracted. Criticisms of traditional anonymous peer review allege that it lacks accountability, can lead to abuse by reviewers, and may be biased and inconsistent [13-15].

The Journal of Obstetrics \& Gynecology of India follows the "double-blind" peer review policy. This means that the reviewers of the paper would not get to know the identity of the author(s), and the author(s) would not get to know the identity of the reviewer. The idea is that everyone should get a similar and unbiased review.

The message to all authors is to consider quality in your written work at all stages of the production process, from before the paper is written right up until when it is finally submitted to our journal. Finally, never be discouraged. Many papers that have been rejected by one journal following peer review, have been submitted and accepted in another, sometimes without revision; and many of these have then later been recognized as being truly important contributions in their field.

Most potential referees are authors themselves, or at least readers, who know that the publication system requires that experts donate their time selflessly to further science. Referees also have the opportunity to prevent work that does not meet the standards of the field from being published, which is a position of some responsibility. The journal today needs your time and expertise.

To give real service you must add something which cannot be bought or measured with money, and that is sincerity and integrity.

-Douglas Adams

\section{References}

1. Wagner WE, Steinzor R, editors. A Brief history of peer review, rescuing science from politics: regulation and the distortion of scientific research. UK: Cambridge University Press; 2006. p. $220-1$.

2. Committee on Science, Engineering \& Public Policy. On being a scientist-responsible conduct in research publication \& openness. National Academy of Sciences. Washington, DC: National Academy Press; 1995. p. 9-12.

3. Select Committee on Science and Technology. Written evidence. The origin of the scientific journal and the process of peer review. The United Kingdom Parliament, Annex 1, July 2004.

4. Spier R. The history of the peer-review process. Trends Biotechnol. 2002;20(8):357-8. doi:10.1016/S0167-7799(02)019856.PMID12127284.

5. History of the Journal. Nature: Timeline publisher. http://www. nature.com/nature/history/timeline_1960s.html. Accessed Feb 2014.

6. Zimmer C. This paper should not have been published. http://www.slate.com/articles/health_and_science/science/2010/ 12/this_paper_should_not_have_been_published.html. Accessed Feb 2014.

7. Cohen PC. Scholars test web alternative to peer review. The New York Times. August 23, 2010. http://www.nytimes.com/2010/08/ 24/arts/24peer.html?_r=2\&ref=arts. Accessed Feb 2014. 
8. Gordon AB. University presses. In: Guthrie JW, editor. Encyclopedia of education, vol. 7. 2nd ed. New York: Macmillan Reference USA; 2003. p. 2601. ISBN 0-02-865601-6.

9. O'Gorman L. The (frustrating) state of peer review. IAPR Newslett. 2008;30(1):3-5

10. Afifi M. Reviewing the "Letter-to-editor" section in the Bulletin of the World Health Organization, 2000-2004. Bulletin of the World Health Organization. http://www.who.int/bulletin/bulletin_ board/84/letters/en/.

11. Lee K. Peer review is not currently designed to detect deception, nor does it guarantee the validity of research findings. "Increasing accountability". Nature. 2006. doi:10.1038/nature05007.

12. Baxt WG, Waeckerle JF, Berlin JA, et al. Who reviews the reviewers? Feasibility of using a fictitious manuscript to evaluate peer reviewer performance. Ann Emerg Med. 1998;32(3 Pt 1):310-7. doi:10.1016/S0196-0644(98)70006-X.PMID9737492.

13. Rothwell PM, Martyn CN. Reproducibility of peer review in clinical neuroscience: is agreement between reviewers any greater than would be expected by chance alone? Brain. 2000;123(9):1964-9. doi:10.1093/brain/123.9.1964.

14. Rowland F. The peer review process-a report to the JISC Scholarly Communications Group. http://www.jisc.ac.uk/ uploaded_documents/rowland.pdf.

15. McCook A. Is peer review broken? The Scientist February 1, 2006. http://www.the-scientist.com/?articles.view/articleNo/ 23672/title/Is-Peer-Review-Broken-/. Accessed Feb 2014. 